\title{
Identity and group dynamics in urban food systems
}

COMMENTARY ON RACE AND ETHNICITY IN FOOD SYSTEMS

\author{
Neetu Choudhary*
}

A. N. Sinha Institute of Social Studies

Submitted June 18, 2015 / Published online September 16, 2015

Citation: Choudhary, N. (2015). Identity and group dynamics in urban food systems. Journal of Agriculture,

Food Systems, and Community Development, 5(4), 153-157. http://dx.doi.org/10.5304/jafscd.2015.054.026

Copyright (C) 2015 by New Leaf Associates, Inc.

\section{Abstract}

In this commentary I argue that access to food and nutrition systems, instead of being uniformly distributed among the urban poor, is a group phenomenon, that is, the shared situation of a group of individuals sharing similar identities, where a group may be defined horizontally in terms of gender, caste, religion, location, and so on. Drawing upon earlier field work in the city of Mumbai in India, I observe that due to identity-driven factors there are certain groups that remain disadvantaged within the food system, while there are groups that are able to attain intergenerational or intertemporal upward mobility despite having similar initial endowments. This happens due to differences between groups in the entitlement relations or due

* Neetu Choudhary, PhD, Assistant Professor of Economics; \#16, A. N. Sinha Institute of Social Studies; Patna, Pin Code 800001, India; choudharyneetu@gmail.com to the relationship between a group's endowment and its exchange options, which in turn is mediated by group members' religious or locational identity. Thus the factor of group dynamics is necessarily inherent within urban food systems, and this can be analyzed through operationalization of the entitlement approach, as proposed by Amartya Sen (1981). The entitlement approach has much potential as a technique for illustrating the power dynamics underlying identity-based group differential in access to urban food systems. In fact, any policy intervention designed to expand individual capabilities, such as nutrition security, would need to be preceded by an analysis of his or her entitlements, including in relation to group affiliations.

\section{Keywords}

group, nutrition, entitlement, food system, slum, endowment, state, agency, transfer 
E xclusion along race, ethnicity, or any other form of identity is essentially an issue of horizontal inequality, that is, inequality across groups. While "poverty," as the class segregation of a group of low-income individuals or households, is a known reason underlying the failure of food systems in the context of developing countries like India, there is much ambiguity about what explains inequality of this failure within the groups collectively called the "poor." In this commentary I argue that access to food and nutrition systems, instead of being uniformly distributed among the urban poor, is a group phenomenon (i.e., the shared situation of a group of individuals with shared identities), where a group may be defined horizontally in terms of gender, caste, religion, location, and so on. Drawing upon earlier field work in the city of Mumbai, India (Choudhary, in press), I observe that due to identity-driven factors there are certain groups that remain disadvantaged within the food system, while there are groups that are able to attain intergenerational or intertemporal upward mobility despite having similar initial endowments. This happens due to differences between groups in resource endowment, on the one hand, and the options to translate those endowments into capabilities, on the other, which in turn is mediated by group members' religious or locational identity. I found that group identity interferes with the processes of local government and public transfer, which are instrumental to (or constraining for) upward intergenerational mobility of population groups in Mumbai. Thus some sort of group dynamics is necessarily inherent within urban food systems, and this can be analyzed through operationalization of the entitlement approach, as proposed by Amartya Sen (1981). In this commentary I share key reflections from entitlement analysis of four slums of Mumbai that help to illustrate the dynamics underlying identitybased group differential in access to urban food systems.

Sen (1981) describes entitlement as the set of all possible combinations of goods and services that an individual can legally obtain using the resources from his or her endowments based on means of production, labor, trade and/or exchange (Osmani, 1993). However, Sen is cognizant of certain "fuzziness" in the notion, likely in transitional contexts, where informal considerations based on social beliefs and attitude towards certain groups take precedence over formal provisions and thus constrain those groups' access to legal entitlements. This is what was observed in the larger study of which this commentary is a part. An analysis of entitlement relation of a person would facilitate understanding of the combination of his or her abilities and social contexts that may result in particular capabilities and associated functioning (see Smith \& Seward, 2009).

\section{Operationalizing the Entitlement Framework}

For the urban poor, labor is the primary individual endowment and source of entitlement. In the four slums that serve as the premises for this commentary, most forms of labor are unskilled and informally employed except one, which has benefitted from the growth of a large formal enterprise in proximity. However, the four slums (namely, Chamunda Nagar, Rafi Nagar, Padma Nagar, and Cheekuvadi) have shared characteristics as far as their initial endowments, that is, the endowments of their first generation in Mumbai, are concerned. It is due to their differential degree of assimilation in the local environment, mediated by informal considerations, that they end up having differential access to urban food systems and as a result suffer from significantly different levels of food and nutrition insecurities. While Chamunda Nagar and Rafi Nagar are on the verge of starvation, Padma Nagar is suffering from chronic malnutrition. Only one of the four slums, Cheekuvadi, is relatively better off and suffers from only moderate levels of malnutrition.

Each of the four slums has a unique identity and social position, although they overlap in some ways. Field reflections identify three main identities that determined the status of the four slums within the urban local food and nutrition systems: migration status, religion, and gender. Further, these three group identities mediate group members' access to overall food systems through three different interfaces.

The first interface is in the form of access to municipal transfer entitlements. Except for 
Cheekuvadi, all the slums in the present study are informal settlements; that is, they are not included in the list of slums in the Greater Mumbai Municipal Corporation (BMC). Of the three non-notified slums, Chamunda Nagar has been created by a cluster of migrants pushed out of their villages in North India. The other two, Rafi Nagar and Padma Nagar, are inhabited by the minority Muslim community, including one inhabited by allegedly illegal in-migrants from the neighboring nation of Bangladesh. Being non-notified, these three slums do not have access to municipal entitlements, including basic civic service supplies such as water and sanitation. This is an important issue given that even the newest of the four slums has existed for nearly 15 years, certainly long enough for social and institutional assimilation. Although it is not a legal violation to not supply municipal civic services to non-notified slums, there are several barriers informally created in the process of legal notification that have become politicized and are unjustifiable on constitutional grounds. The lack of access to drinking water, sanitation, and an overall livable environment has been a central factor also excluding the three slums from access to minimum nutrition systems.

Moreover, the varying degrees of assimilation of the four slums can be attributed to varying social, cultural, and political backdrops in Mumbai corresponding to the emergence of these slums. When Cheekuvadi- the oldest and the now notified among the four slums-emerged, urban space and resources were not a constraint in Mumbai, and therefore neither administrative nor cultural sentiments toward it were hostile. Also, this slum's dwellers are not migrants from outside the state of Maharashtra. Thus attempts were made to mainstream the slum in terms of education, food, and housing support, which proved helpful in facilitating access to urban food and nutrition systems. In the present context, migrants and minority Muslim members are a resented lot amid the identity politics of Mumbai that are driven by Maratha (the originals of Mumbai) sentiments. Growing pressure on urban infrastructure and changing demography in favor of the former have aggravated negative sentiments, and this in turn is contributing toward institutional alienation of the excluded groups.
The second interface is in the form of access to the public food and nutrition support system. The Public Distribution System (PDS) in India is countrywide scheme that entitles some groups of people below the poverty line to food and nutrition support from the state. Access to the PDS is based on beneficiaries' identity cards. Since all four slums except one, Cheekuvadi, are informal settlements of in-migrants, their residents usually fail to establish their identities and are bypassed by the PDS system. Issuance of an identity card itself is constrained partly by the widespread corruption sweeping the PDS machinery and partly by systemic bias against migrants and minority communities in Mumbai. Thus the residents of the three slums need to rely solely on the market for meeting their food needs. The inability to afford to do this has resulted in circumstances of starvation. Clearly, as Stewart (1999) notes, "democratic institutions are not sufficient to prevent such inequalities, partly because majorities can discriminate against minorities, and partly because even with 'shared' power at the top, lower level elements may involve inequalities" (p. 9).

Affiliation with the group identified as migrants from North India or as Muslims is resulting in social exclusion of access to both tangible and nontangible resources. From the perspective of the entitlement framework, all four slums have similar initial endowments; that is, at the beginning of their settlement their only asset is unskilled and illiterate labor. The difference that has arisen since then lies in the differential nature of entitlement relations faced by each of them. Sen's (1981) framework mentions four types of entitlements, namely those based on labor, production, exchange, and transfer. While all four slums share similar supplies of labor-, production- and exchange-based entitlements, it is the transferbased entitlement that is generating differential options for them, as mediated by their respective identities.

The third form of interface emerges from the gendered nature of food and nutrition systems that influences a group's ability to translate resources into functionality. Since determinants of malnutrition include several nonfood and nontangible factors, such as health care, reproductive health, 
fertility behavior, etc., access to food and cash may not solve the problem completely. The instrumental relationship between low income and low capability is variable between different communities (Sen, 1999). Like food utilization and care practices, intracommunity gender dynamics also usually manifest themselves through cultural beliefs and practices. Gendered processes are salient manifestations of cultural norms in less developed contexts, often resulting in intrahousehold discrimination in food and nutrition entitlement (Agarwal, 1996). For example, based on household surveys, I found that the extent of health-care outreach was much lower for female children as compared to males in all four slums. Further, negligence of reproductive health is also a manifestation of negligence toward women's health. This is particularly visible within the minority Muslim communities of two slums, where women are burdened by repeated child-bearing due to religious taboos. The low status of women, uncontrolled fertility, and poor reproductive health care-key factors behind mother-child transmission of malnutrition - are typical of Rafi Nagar and Padma Nagar, both of which are home primarily to Muslims.

The varying nature of entitlement relation and differential degree of entitlement failure between the four slums are lucid representations of the intersection of class, religion, migration status, and gender. Entitlement collapse of the highest degree occurs when a group is on the disadvantaged side simultaneously in respect of all four dimensions (Joe, 2013). Even if overall malnutrition rates in urban areas may be lower than in the countryside, the three slums in this commentary (excluding Cheekuvadi) show that there are pockets of extreme vulnerability. Thus a reduced rate of malnutrition may not imply a reduction in inequality related to it (Van de Poel, Hosseinpoor, Speybroeck, Van Ourtia, \& Vega, 2008). Among the four settlements, only Cheekuvadi experienced upward mobility over the years. Though the four slums were endowed with similarly inadequate resources at their founding, due to the ease of assimilation in the host environment supported by public transfer to its earlier generation, one of them has been able to escape extreme vulnerability.
The remaining three slums seem to be trapped in persistent vulnerability. These three slums do not display any sign of upward mobility, and the younger generation in these slums witness vulnerability transfer from their parents; this is, they inherit poverty (South African Human Rights Commission [SAHRC] \& UNICEF, 2014). Given their meager labor options and disparity in access, the three slums are structurally less capable of assimilation into mainstream processes. They also are unable to defend their rights due to the high transaction costs of accessing formal juridical systems (see Birner, 2007). The kinds of deficiency they are suffering from causes long-term impairment related to nutrition and cognitive ability, and it takes a very long time to reverse the process. In such a scenario, tackling deprivation and poverty among vulnerable groups may require tackling the position of the group as well (see Stewart 2007). It is in the ability to problematize this dimension of nutritional vulnerability that the contribution of entitlement framework lies. Even though Sen's entitlement approach has received several criticisms (see De Waal, 1990; Gore, 1993), much of these criticisms are resolved once the entitlement approach is considered as a framework to explore a plurality of causes and to analyze the relationship between rights, interpersonal obligations, and individual entitlement to things (see Vizard, 2001).

To conclude, I argue that the issue of nutrition security has an indispensable and direct role for the state's agency, especially in the wake of the identity-based discriminations observed amid food system dynamics at the local level. Given the culturally diverse nature of Indian society, there is much scope for mediation of food access by identitybased issues such as race, caste, religion, or gender. While the role of civil society and community leaders becomes critical in this regard, this does not absolve the state of its obligations to guarantee constitutional rights to its people. Despite their importance in political dynamics, identity-based discriminations have failed to receive adequate attention in the processes of development intervention. Thus issues such as race, religion, caste, and migration status continue to distort groups' entitlement structures and their access to basic survival options. 


\section{References}

Agarwal, B. (1996). A field of one's own: Gender and land rights in South Asia. Cambridge, UK: Cambridge University Press.

Birner, R. (2007). Improving governance to eradicate hunger and poverty (IFPRI 2020 Focus Brief on World's Poor and Hungry People). Retrieved from the International Food Policy Research Institute website: http://www.ifpri.org

Choudhary, N. (in press). Malnutrition in greater Mumbai slums: An entitlement analysis of group differentials in basic capabilities. South Asia Research.

De Waal, A. (1990). A re-assessment of entitlement theory in the light of the recent famines in Africa. Development and Change, 21(3), 469-490. http://dx.doi.org/10.1111/j.14677660.1990.tb00384.x

Gore, C. (1993). Entitlement relations and 'unruly' social practices: A comment on the work of Amartya Sen. Journal of Development Studies, 29(3), 429-460. http://dx.doi.org/10.1080/00220389308422283

Joe, W. (2013, August). Inter-group inequalities in child undernutrition in India: Intersecting caste, gender and place of residence. Poster presented at the meeting of the International Union for the Scientific Study of Population, Busan, Republic of Korea. http://iussp.org/sites/default/files/event call.../ William\%20310\%20Paper.pdf

Osmani, S. R. (1993). The entitlement approach to famine: An assessment (WIDER Working Paper No. 107). Retrieved from the World Institute of Development Economics Research (WIDER) website: http://www.wider.unu.edu
South African Human Rights Commission [SAHRC] \& UNICEF. (2014). Poverty traps and social exclusion among children in South Africa. Pretoria: SAHRC. Retrieved from http://www.sahrc.org.za/home/ 21/files/Poverty $\% 20$ Traps $\% 20$ Report.pdf

Sen, A. (1999). Development and freedom. Oxford: Oxford University Press.

Sen, A. (1981). Poverty and famines: An essay on entitlement and deprivation. Oxford: Clarendon Press.

Smith, M. L., \& Seward, C. (2009). The relational ontology of Amartya Sen's capability approach: Incorporating social and individual causes. Journal of Human Development and Capabilities, 10, 213-235. http://dx.doi.org/10.1080/19452820902940927

Stewart, F. (2007). Why horizontal inequalities matter. Poverty in Focus, June, 16-17. Retrieved from http://www.ipc-undp.org/publication/27313

Stewart, F. (1999, June). Crisis prevention: Tackling horizontal inequalities. Paper presented at the World Bank Conference on Evaluation and Poverty Reduction, Washington, D.C.

Van de Poel, E., Hosseinpoor, A. R., Speybroeck, N., Van Ourtia, T., \& Vega, J. (2008). Socioeconomic inequality in malnutrition in developing countries. Bulletin of the World Health Organization, 86(4), 241320. http://www.who.int/bulletin/volumes/86/ 4/07-044800/en/

Vizard, P. (2001). Economic theory, freedom and human rights: The work of Amartya Sen (ODI Briefing Paper). Retrieved from the Overseas Development Institute (ODI) website: http://www.odi.org 